\title{
Knock-Down of Gossypol-Inducing Cytochrome P450 Genes Reduced Deltamethrin Sensitivity in Spodoptera exigua (Hübner)
}

\author{
Muhammad Hafeez ${ }^{1}\left(\mathbb{D}\right.$, Sisi Liu ${ }^{2, *} \mathbb{*}$, Saad Jan ${ }^{3}$, Le Shi ${ }^{1}$, G. Mandela Fernández-Grandon ${ }^{4}(\mathbb{D}$, \\ Asim Gulzar ${ }^{5}$, Bahar Ali ${ }^{1}$, Muzammal Rehman ${ }^{6}$ and Mo Wang ${ }^{1, *}$ \\ 1 Hubei Insect Resources Utilization and Sustainable Pest Management Key Laboratory, College of Plant \\ Science and Technology, Huazhong Agricultural University, Wuhan 430070, Hubei, China; \\ drhafeez@webmail.hzau.edu.cn (M.H.); leshi@webmail.hzau.edu.cn (L.S.); \\ bahardirvi@webmail.hzau.edu.cn (B.A.) \\ 2 Laboratory of medicinal Biophysical Chemistry, College of Science, Huazhong Agricultural University, \\ Wuhan 430070, Hubei, China \\ 3 Department of Agriculture Entomology Section, Bacha Khan University, Charsadda 24630, Pakistan; \\ drsaadjan@bkuc.edu.cn \\ 4 Natural Resources Institute, University of Greenwich, Chatham Maritime, Kent, Gillingham ME4 4TB, UK; \\ m.fernandez-grandon@greenwich.ac.uk \\ 5 Department of Entomology, Pir Mehr Ali Shah Arid Agriculture University, Rawalpindi, Punjab 46000, \\ Pakistan; asim@uaar.edu.pk \\ 6 MOA Key Laboratory of Crop Ecophysiology and Farming System in the Middle Reaches of the Yangtze \\ River, College of Plant Science and Technology, Huazhong Agricultural University, Wuhan 430070, Hubei, \\ China; muzammal@webmail.hzau.edu.cn \\ * Correspondence: liusisi@mail.hzau.edu.cn (S.L.); wangmo@mail.hzau.edu.cn (M.W.)
}

Received: 16 March 2019; Accepted: 1 May 2019; Published: 7 May 2019

Abstract: Plants employ an intricate and dynamic defense system that includes physiological, biochemical, and molecular mechanisms to counteract the effects of herbivorous attacks. In addition to their tolerance to phytotoxins, beet armyworm has quickly developed resistance to deltamethrin; a widely used pyrethroid insecticide in cotton fields. The lethal concentration $\left(\mathrm{LC}_{50}\right)$ required to kill $50 \%$ of the population of deltamethrin to gossypol-fed Spodoptera exigua larvae was 2.34-fold higher than the control group, suggesting a reduced sensitivity as a consequence of the gossypol diet. Piperonyl butoxide (PBO) treatment was found to synergize with deltamethrin in gossypol-fed S. exigua larvae. To counteract these defensive plant secondary metabolites, beet armyworm elevates their production of detoxification enzymes, including cytochrome $\mathrm{P} 450$ monooxygenases (P450s). Gossypol-fed beet armyworm larvae showed higher 7-ethoxycoumarin-O-deethylase (ECOD) activities and exhibited enhanced tolerance to deltamethrin after 48 and $72 \mathrm{~h}$ when compared to the control. Moreover, gossypol pretreated S. exigua larvae showed faster weight gain than the control group after transferring to a deltamethrin-supplemented diet. Meanwhile, gossypol-induced P450s exhibited high divergence in the expression level of two P450 genes: CYP6AB14 and CYP9A98 in the midgut and fat bodies contributed to beet armyworm tolerance to deltamethrin. Knocking down of CYP6AB14 and CYP9A98, via double-stranded RNAs (dsRNA) in a controlled diet, rendered the larvae more sensitive to the insecticide. These data demonstrate that generalist insects can exploit secondary metabolites from host plants to enhance their defense systems against other toxic chemicals. Impairing this defense pathway by RNA interference (RNAi) holds a potential to eliminate the pest's tolerance to insecticides and, therefore, reduce the required dosages of agrochemicals in pest control.

Keywords: Spodoptera exigua; deltamethrin tolerance; gossypol; detoxification; midgut P450 genes; RNA interference 


\section{Introduction}

Plants respond to herbivory through an intricate and dynamic defense system that includes physiological, biochemical, and molecular mechanisms to counteract the effects of insect attacks $[1,2]$. The arms race for the insects to overcome these changing plant defenses leads to implications for their behavior and fitness [3]. Previous studies revealed that different types of plant secondary metabolites have been shown resistance by acting as feeding deterrents, toxins, and growth inhibitors against several insect orders including Coleoptera, Lepidoptera, and Hymenoptera [4-6]. Gossypol and related sesquiterpene aldehydes are the main secondary metabolites in cotton plants and have been shown to possess insecticidal activities and fungistatic properties [7,8].

However, the phytophagous insect does not act as a passive victim. It has been documented that, to detoxify or tolerate a variety of toxic compounds produced by plants or other sources, insects have evolved sophisticated defense system to elevate the activities of detoxification enzymes, such as esterase, glutathione S-transferases, and cytochrome P450 monooxygenases [9-11]. Cytochrome P450s (CYPs) are a large gene family of multifunctional enzymes which are involved in both metabolic detoxification of plant secondary metabolites and chemical insecticides in herbivorous insects $[10,12]$. The insect detoxification system mainly consists of transferring, metabolizing, and excreting of toxic compounds [13]. A variety of P450 substrate recognition sites induce the metabolic malleability, meaning that manifold P450 genes can metabolize a single substrate, or one P450 gene can metabolize a number of different substrates [14]. A large number of detoxification-related P450s genes from insects have been isolated and identified, many of which belong to the CYP6 family $[14,15]$. For example, gossypol-induced P450s showed high divergence, of which at least five of them (CYP6AE11, CYP321A1, CYP9A12, CYP9A14, and CYP6B7) contributed to the tolerance of deltamethrin insecticide in cotton bollworm (Helicoverpa armigera) [16]. Additionally, CYP6AS in the honey bee, Apis mellifera, could metabolize the flavonoid quercetin [17]. Further studies have shown that the expression of five P450 genes (CYP9A14, CYP337B1, CYP9A12, CYP6AE11, and CYP6B7) in the resistant strains of $H$. armigera was significantly higher in response to fenvalerate pesticides $[18,19]$. Cross-resistance of alpha-cypermethrin after ingestion of xanthotoxin in Helicoverpa zea and high expression response of P450s genes (CYP6B2, CYP6B6, CYP6B7, CYP6B8 and CYP321A1) were observed in quercetin fed larvae of $H$. armigera $[11,20]$ In addition, insecticide resistance was found to be different in populations fed on different host plant species [21], indicating that the host plant and its secondary metabolites may affect insect susceptibility to pesticides. As the main phytotoxin of cotton, gossypol plays an important role in shaping the defensive state of beet armyworm.

For decades chemical pesticides have been a common approach for controlling vector-borne diseases and insect pests in crop systems. Synthetic pyrethroids are considered to be effective insecticides for insect pest control and play a significant role in reducing crop losses caused by herbivores insects [22]. However, extensive usage of insecticides has lowered their efficacy due to the development of insect resistance. Increasingly, concern is also raised about the environmental pollution and human health issues that they cause. Beet armyworm, Spodoptera exigua, is a major insect pest that feeds on many economically important crops globally. In China, it is particularly responsible for extensive losses in the vegetable, ornamental plant, and cotton sector [23]. Chemical insecticides have been extensively used for control of this pest which has led to strong selection of strains resistant to pyrethroids and more recently developed chemistries [24-27]. This, in turn, has led to the failure of traditional control strategies in the field [28]. A newer and promising strategy that could have a significant impact on the economy of agriculture is the implementation of RNA interference (RNAi). RNAi is an efficient technique in the study of insect resistance and could play a significant role in pests control [24]. In numerous insects, RNAi techniques have been applied to partially silence P450 genes responsible for insecticide resistance, such as CYP9A14 [16], CYP6AE14 [12] or CYP9A21v3 [24]. In addition, transgenic plants expressing double-stranded RNAs (dsRNA) have exhibited effect control for pests. The expression of P450 genes has been found to decrease dramatically when the larvae of $H$. armigera were fed on transgenic cotton plants expressing CYP6AE14 as a result of physiological 
impact, such as loss of appetite, growth retardation, and ultimately death [12]. RNAi has also been used to study the Escherichia coli-expressed dsRNA of SeCHSA in S. exigua. When S. exigua larvae were fed E. coli expressing the dsRNA of SsCHSA (chitin synthase gene A), it led to significant reductions in survival rates of the S. exigua [29]. These advances in our understanding of RNA interference as a tool in insect pest regulation may pave the way for its development for wider, commercial usage.

This study was conducted to explore the effect of plants secondary metabolites on tolerance of S. exigua larvae to deltamethrin. We measure the P450 midgut detoxification enzyme activity toward specific substrates to demonstrate the biochemical characteristics of gossypol-stimulated tolerance to deltamethrin. In addition, we examined the potential role of cytochrome P450 genes in detoxification of plant secondary metabolites and pyrethroid insecticides in S. exigua larvae. The tissue-specific expression patterns of CYP450 genes and its potential role in synthetic pyrethroid insecticide detoxification were studied by quantitative real-time-PCR. RNA interference was used to downregulate the CYP6AB14 and CYP9A98 genes. These results provide important insight into the role of CYP450 genes in detoxification of gossypol-pretreated deltamethrin resistance and may be essential in the development of novel methods for the control of S. exigua.

\section{Results}

\subsection{Induced Effect of Gossypol to Deltamethrin Tolerance and Synergism Assessment}

To find out the effect of plant secondary metabolites on insecticide tolerance, we examined the induced effect of gossypol-supplemented diet on the sensitivity of S. exigua larvae to deltamethrin, a widely used pyrethroid insecticide in many crops including cotton. We found that deltamethrin showed lowered toxicity to the S. exigua larvae fed on an artificial diet supplemented with $1 \%$ gossypol per gram of diet than it did in the gossypol-free control group. We also found that lethal concentration to $50 \%\left(\mathrm{LC}_{50}\right)$ value of deltamethrin to the gossypol-fed third instar S. exigua larvae was higher $(1.704 \mathrm{mg} / \mathrm{L})$ while the lower $\mathrm{LC}_{50}$ value was observed for the control diet $(0.887 \mathrm{mg} / \mathrm{L})($ Table 1$)$. Furthermore, the synergism assay indicated that $\mathrm{PBO}$ treatment as a synergist effectively increased the deltamethrin efficacy in gossypol-fed larvae with a synergism ratio 1.7 as compared to the control group in which PBO showed low synergism to deltamethrin. These results showed that a gossypol-supplemented diet increased the level of tolerance to deltamethrin insecticide.

Table 1. The influences of gossypol ingestion and synergism effect of piperonyl butoxide (PBO) on the deltamethrin toxicity to S. exigua larvae.

\begin{tabular}{cccccccc}
\hline Treatment & $\mathbf{N}$ & LC $_{\mathbf{5 0}} \mathbf{( m g}$ a.i./L) & $\mathbf{9 5 \%} \mathbf{C L}$ & Slope $\pm \mathbf{S E}$ & $\mathbf{d f}$ & $\chi^{\mathbf{2}}$ & SR \\
\hline Control & 420 & 0.887 & $0.75 \pm 1.03$ & $1.56 \pm 0.14$ & 4 & 1.66 & 1.7 \\
Control + PBO & 420 & 0.681 & $0.58 \pm 0.79$ & $1.61 \pm 0.14$ & 4 & 0.79 & - \\
Gossypol & 420 & 1.704 & $1.46 \pm 1.98$ & $1.71 \pm 0.15$ & 4 & 1.24 & - \\
Gossypol + PBO & 420 & 0.735 & $0.61 \pm 0.87$ & $1.47 \pm 0.14$ & 4 & 1.979 & 2.3 \\
\hline
\end{tabular}

$\mathrm{N}$ : number of insects, CL: confidence limits, df: degrees of freedom, $\chi 2$ : Chi-square value.

\subsection{Effect of Gossypol Diet on Larval Body Weight}

To observe the induced effect of gossypol on the net larvae weight of S. exigua, gossypol-supplement and control diet was fed to third instar larvae for one day before being transferred to a diet containing $\mathrm{LC}_{50}$ concentration of deltamethrin. Net weight increased in gossypol-pretreated larvae on deltamethrin-supplemented diet significantly faster than was observed in the control diet after $48 \mathrm{~h}$, while the most obvious different body weight gain increased in gossypol-pretreated larvae on deltamethrin-supplemented diet and control treatment at $72 \mathrm{~h}$ (Figure 1). 


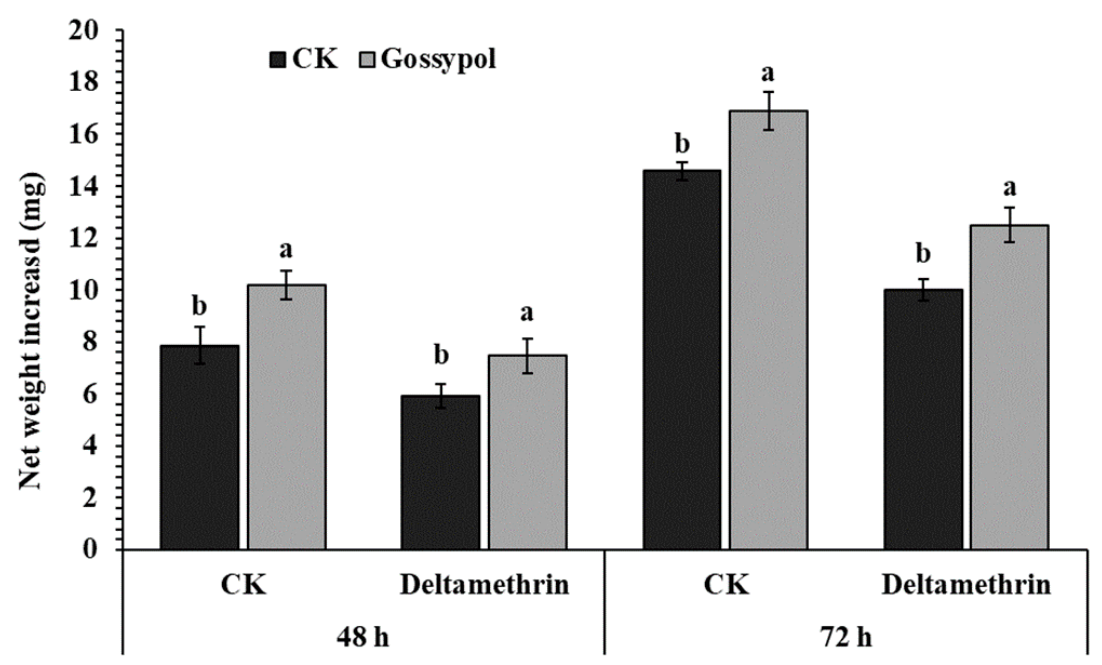

Figure 1. Net weight increase in gossypol-pretreated larvae on deltamethrin-supplemented diet. The early third instar larvae had previously fed on control (CK) or $1 \mathrm{mg} / \mathrm{g}$ gossypol-supplemented (Gossypol) diet for 1 day; after recording the initial weight, two independent groups of each treatment were transferred to $0.887 / \mathrm{L}$ deltamethrin-supplemented diet and control diet, respectively, weight increases were recorded 2 days later. Error bars represent standard deviation. Different letters above bars indicate significant differences $(p<0.05)$ according to the Student's $t$-test.

\subsection{Effect of Gossypol on Midgut P450 Activity}

To determine the biochemical properties of the gossypol-induced effect on deltamethrin tolerance to the fourth instar S. exigua larvae, the activity of P450 detoxification enzyme in midguts was analyzed (Figure 2). Results indicate that P450 detoxification enzyme activity in the midgut of S. exigua larvae was significantly elevated in artificial diets supplemented with $0.1 \%$ gossypol, $\mathrm{LC}_{50}$ concentration of deltamethrin $0.887 \mathrm{mg} / \mathrm{L}$ for 48 and $72 \mathrm{~h}$ or $0.1 \%$ gossypol for $24 \mathrm{~h}$ followed by deltamethrin for 48 and $72 \mathrm{~h}$ when compared to the control group (Figure 2). In addition, significantly higher activity was observed in $0.1 \%$ gossypol for $24 \mathrm{~h}$ followed by deltamethrin for 48 and $72 \mathrm{~h}$ when compared to other treatments, respectively.

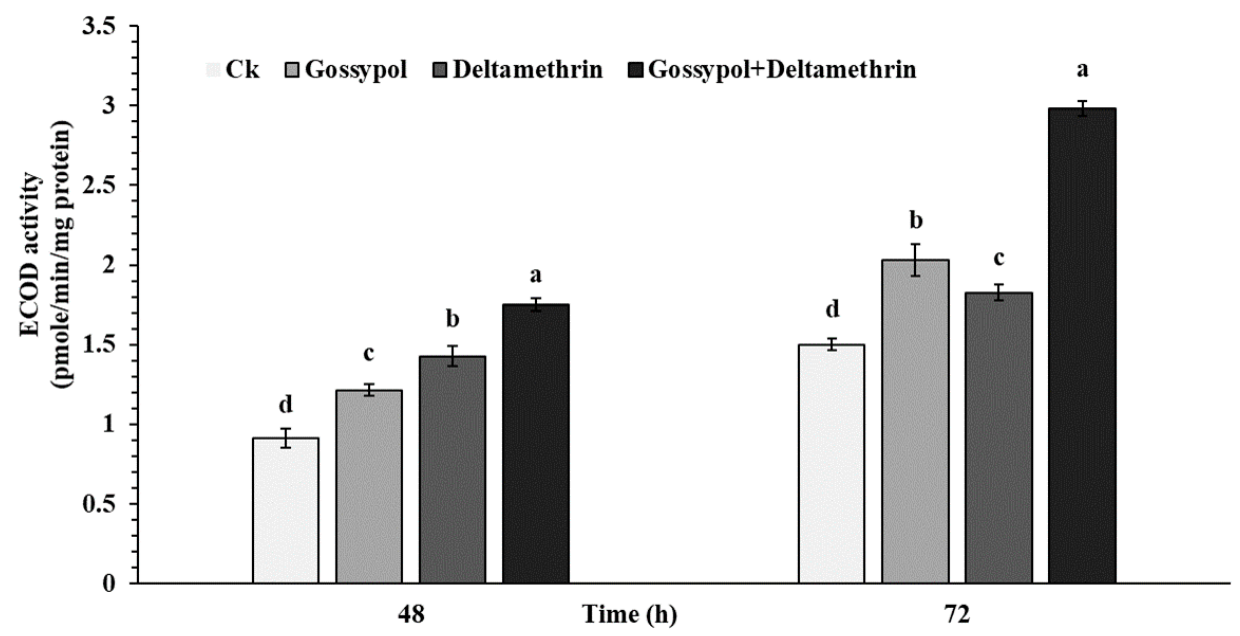

Figure 2. Induced effects of gossypol on beet armyworm tolerance to deltamethrin and O-deethylase activity of P450s after 48 and $72 \mathrm{~h}$ in forth instar. The early forth instar larvae were transferred into new sterilized plastic cups containing artificial diets supplemented with $0.1 \%$ gossypol, $\mathrm{LC}_{50}$ concentration of deltamethrin $0.887 \mathrm{mg} / \mathrm{L}$ for 48 and $72 \mathrm{~h}$ or $0.1 \%$ gossypol for $24 \mathrm{~h}$ followed by deltamethrin for 48 and $72 \mathrm{~h}$. Data shown are means \pm SE derived from three biological replicates. Different letters above bars indicate significant differences $(p<0.05)$ according to the Tukey HSD test. 


\subsection{Effect of Gossypol, Flavone, and Deltamethrin on Expression Response of P450 Genes}

The induced effect of gossypol to deltamethrin tolerance on the expression level of CYP6AB14, CYP9A12, and CYP9A98 was examined in midguts and fat bodies of S. exigua (Figure 3). Fourth instar S. exigua larvae were exposed to plant allelochemicals $1.0 \%$ gossypol, $1.0 \%$ flavone, and deltamethrin insecticide for $72 \mathrm{~h}$ and gossypol for one day followed by deltamethrin for $72 \mathrm{~h}$ in two tissues (midguts and fat bodies) of S. exigua larvae. The expression level of CYP6AB14 was significantly increased in the midgut (gossypol: 5.4, deltamethrin: 4.0 and gossypol+deltamethrin: 7.8-fold) and fat bodies (gossypol: 5.4, deltamethrin: 4.3 and gossypol+deltamethrin: 6.8-fold). In addition, a 7.8-fold higher CYP6AB14 expression level was observed for gossypol+deltamethrin treated fourth instar larvae in midguts after $72 \mathrm{~h}$ compared with the control group (Figure 3). Similarly, significantly increased CYP9A12 expression level was also observed in midgut and fat bodies in treated groups as compared with the control groups. Following treatment, steady-state expression level was observed for CYP9A98 in the midgut (gossypol: 2.49, deltamethrin: 6.29 and gossypol+deltamethrin: 4.39 fold) and fat bodies (gossypol: 2.5, deltamethrin: 5.0 and gossypol+deltamethrin: 4.1 fold) (Figure 3). The maximum increase in CYP6AB14 expression was observed for gossypol+deltamethrin in midguts and fat bodies. In comparison with marked induction by gossypol, CYP6AB14, CYP9A12, and CYP9A98 were weakly induced by flavone, which exerted little or no effect.
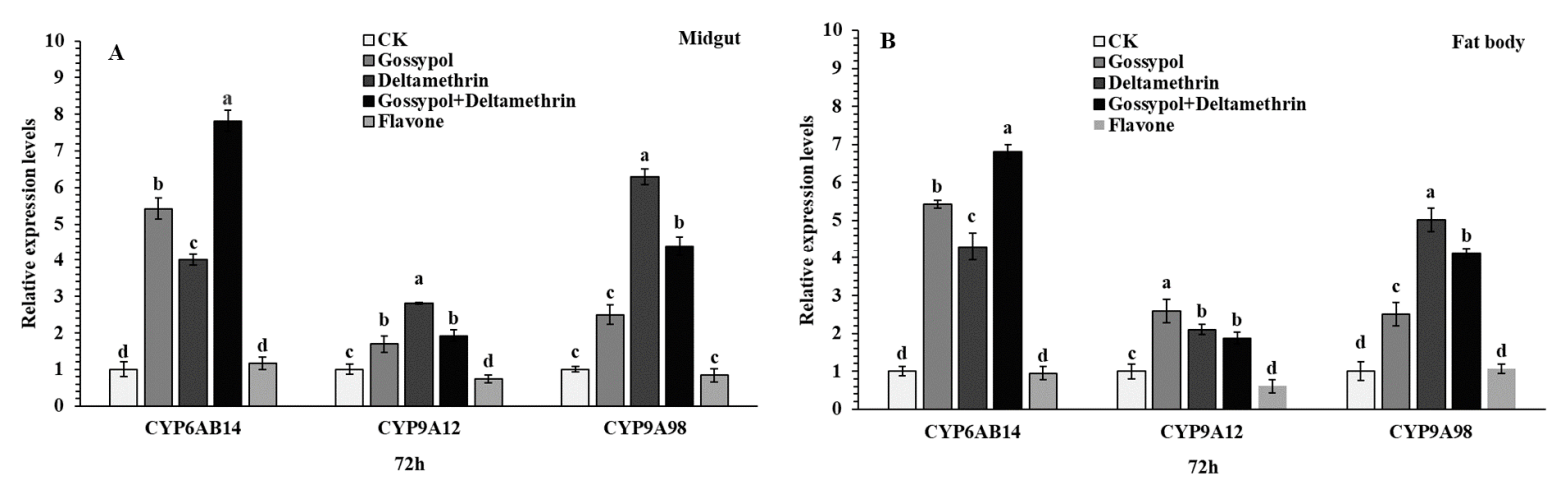

Figure 3. Effect of gossypol on beet armyworm tolerance to deltamethrin and relative expression levels of three P450s genes in midgut (A) and fat body (B) of S. exigua. Late third instar larvae were transferred into new sterilized plastic cups containing artificial diets supplemented with $0.1 \%$ gossypol, $\mathrm{LC}_{50}$ concentration of deltamethrin $0.887 \mathrm{mg} / \mathrm{L}$ for $72 \mathrm{~h}$ or $0.1 \%$ gossypol for $24 \mathrm{~h}$ followed by deltamethrin for $72 \mathrm{~h}$. Data shown are means $\pm \mathrm{SE}$ derived from three biological replicates. The transcription levels of three P450s genes determined by quantitative real-time PCR, normalized to three reference genes Different letters above bars indicate significant differences $(p<0.05)$ according to the Tukey HSD test.

\subsection{Effect of dsCYP6AB14 and dsCYP9A98 on Larval Mortality}

Mortality of fourth instar larvae of S. exigua via droplet-fed $d s R E D, d s C Y P 6 A B 14$, and $d s C Y P 9 A 98$ for $24 \mathrm{~h}$ and followed by feeding on $0.1 \%$ gossypol, $\mathrm{LC}_{50}$ concentration of deltamethrin $0.887 \mathrm{mg} / \mathrm{L}$ for $72 \mathrm{~h}$ and then $0.1 \%$ gossypol for $24 \mathrm{~h}$ before being transferred to deltamethrin for a further $72 \mathrm{~h}$. In the control group, a standard diet was provided. This result indicated the feeding of $d_{s} C Y P 6 A B 14$ and $d s C Y P 9 A 98$ larvae significantly increased the toxicity of gossypol and deltamethrin. Larval droplet feeding with dsCY P6AB14 significantly increased the larval mortality caused by gossypol (16.66\%), deltamethrin (20\%), and gossypol+deltamethrin (41.33\%). Similarly, dsCYP9A98 feeding led to increased mortality in gossypol $(8.33 \%)$, deltamethrin $(28.33 \%)$, and gossypol+deltamethrin $(31.66 \%)$ compared with control dsRED, which was for gossypol (8.33\%) deltamethrin (13.3\%), and gossypol+deltamethrin (21.66\%) at $48 \mathrm{~h}$ (Figure 4). Increased mortality was also observed at $72 \mathrm{~h}$ for $d_{s} C Y P 6 A B 14$ fed larvae transferred on diet supplemented with gossypol (31.66\%), deltamethrin (38.33\%), and gossypol+deltamethrin (65\%) and for $d_{S C Y P 9 A 98}$ fed larvae on diet supplemented with gossypol (18.33\%), deltamethrin $(48.24 \%)$, and gossypol+deltamethrin (53.33\%) as compared with the $d s R E D$ control group at $72 \mathrm{~h}$, which showed 
lower mortality rates for gossypol (21.33\%), deltamethrin (26.66\%), and gossypol+deltamethrin (36.66\%) (Figure 4). The progression of mortality in dsRNA treated normal larvae and mortality assays the mock controls have been shown in Figure S1.

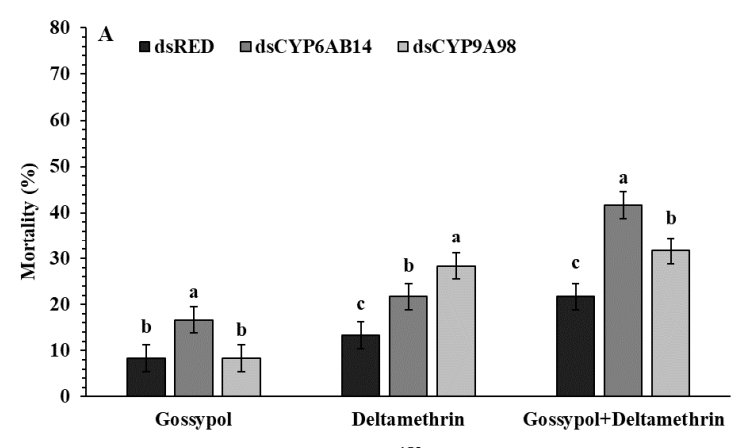

$48 \mathrm{~h}$

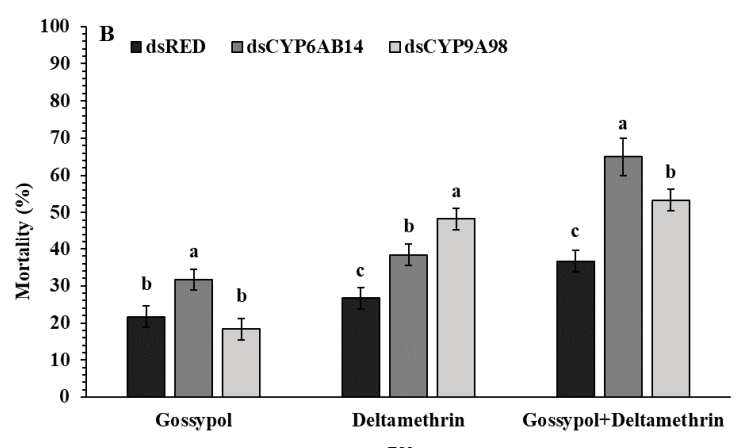

$72 \mathrm{~h}$

Figure 4. Single effects of $d_{s} C Y P A B 14$ and $d s C Y P A 98$ feeding on the susceptible of fourth instar S. exigua

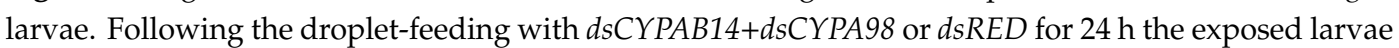
were transferred individually into 12-oriface tissue culture plate containing artificial diets supplemented with $0.1 \%$ gossypol, $\mathrm{LC}_{50}$ concentration of deltamethrin $0.887 \mathrm{mg} / \mathrm{L}$ for $48(\mathrm{~A})$ and $72 \mathrm{~h}(\mathbf{B})$ or $0.1 \%$ gossypol for $24 \mathrm{~h}$ followed by deltamethrin for 48 (A) and $72 \mathrm{~h}(\mathbf{B})$. Data shown are means $\pm \mathrm{SE}$ derived from three biological replicates. Different letters above bars indicate significant differences $(p<0.05)$ according to the Tukey HSD test.

\subsection{The Combined Effect of Target dsCYP6AB14+dsCYP9A98 Genes on Larval Mortality}

Target genes $d_{s} C Y P 6 A B 14+d s C Y P 9 A 98$ combination was prepared at the final concentration of $1000 \mathrm{ng} / \mu \mathrm{l}$. After combined application of dsRNA, the larval mortality was significantly increased which showed $23.33 \%, 36.66 \%$, and $48.33 \%$ for gossypol, deltamethrin, and gossypol+deltamethrin, respectively at $48 \mathrm{~h}$ compared with the ds-RED which showed $8.33 \%, 16.66 \%$, and $26.66 \%$ for the same treatments (Figure 5). Similarly, mortality of S. exigua larvae fed on $d s C Y P 6 A B 14+d s C Y P 9 A 98$ following the exposure to gossypol, deltamethrin, and gossypol+deltamethrin was significantly increased after $72 \mathrm{~h}$ showing the mortality rate for gossypol, deltamethrin, and gossypol+deltamethrin of $36.33 \%$, $63.33 \%$, and $81.66 \%$, respectively, compared with the ds-RED as a control treatment (Figure 5). In the end, the data showed a fascinating combined effect of $d s_{s} C Y P 6 A B 14+d s C Y P 9 A 98$ on the mortality of S. exigua larvae.

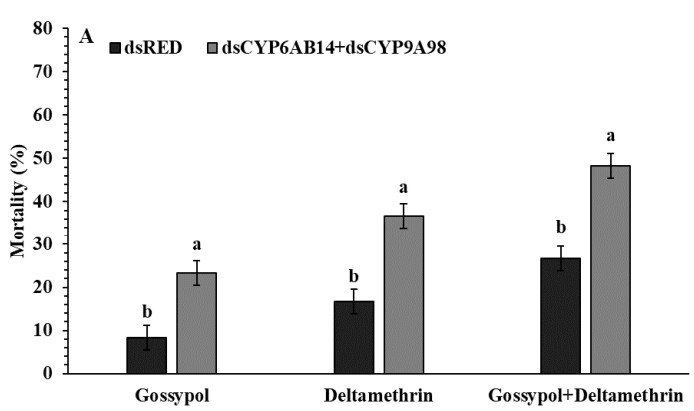

48h

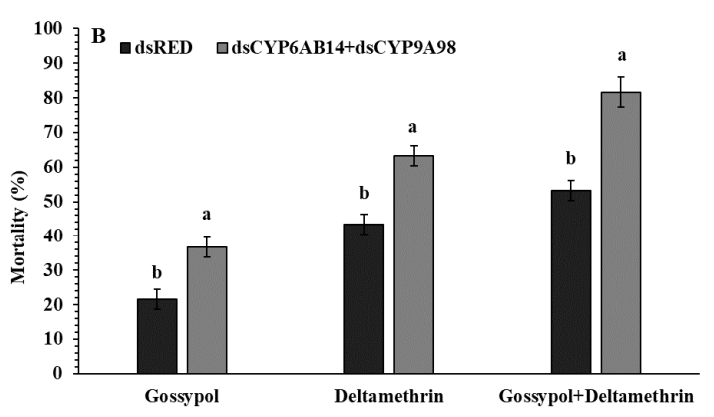

$72 \mathrm{~h}$

Figure 5. Combined effect of $d_{s} C Y P A B 14+d_{s} C Y P A 98$ feeding on the mortality of fourth instar S. exigua larvae. Following the droplet-feeding with $d_{s} C Y P A B 14+d s C Y P A 98$ or $d s R E D$ for $24 \mathrm{~h}$ the exposed larvae were transferred individually into 12-oriface tissue culture plate containing artificial diets supplemented with $0.1 \%$ gossypol, $\mathrm{LC}_{50}$ concentration of deltamethrin $0.887 \mathrm{mg} / \mathrm{L}$ for 48 (A) and $72 \mathrm{~h}(\mathbf{B})$ or $0.1 \%$ gossypol for $24 \mathrm{~h}$ followed by deltamethrin for 48 (A) and $72 \mathrm{~h}(\mathbf{B})$. Data shown are means \pm SE derived from three biological replicates. Different letters above bars indicate significant differences $(p<0.05)$ according to the Student's $t$-test. 


\subsection{Effect of Silencing by dsRNA}

To determine whether reduced expression of $d_{s} C Y P 6 A B 14$ and $d_{s} C Y P 9 A 98$ have an effect on the susceptibility of $S$. exigua larvae to gossypol and deltamethrin, RNAi-mediated knockdown effect of these genes was performed on fourth instar larvae of S. exigua exposed to gossypol and deltamethrin. Twenty-four-hour post-treatment to dsRNA via droplet feeding following exposure on gossypol, deltamethrin, or gossypol+deltamethrin led to significant reductions in the expression levels of $d_{s C Y P 6 A B 14}$ and $d_{s C Y P 9 A 98}$ in the midgut and fat bodies at 48 and $72 \mathrm{~h}$, respectively (Figure 6). Furthermore, QRT-PCR results showed that droplet feeding of the combined target genes (dsCYP6AB14+dsCYP9A98) significantly reduced the relative expression levels than the ds-RED control or the individual dsRNA treatments in the midguts and fat bodies after 48 and $72 \mathrm{~h}$ (Figure 6). This result validated that RNAi effectively suppressed the expression of CYP9A105 in S. exigua exposed larvae under the conditions employed.
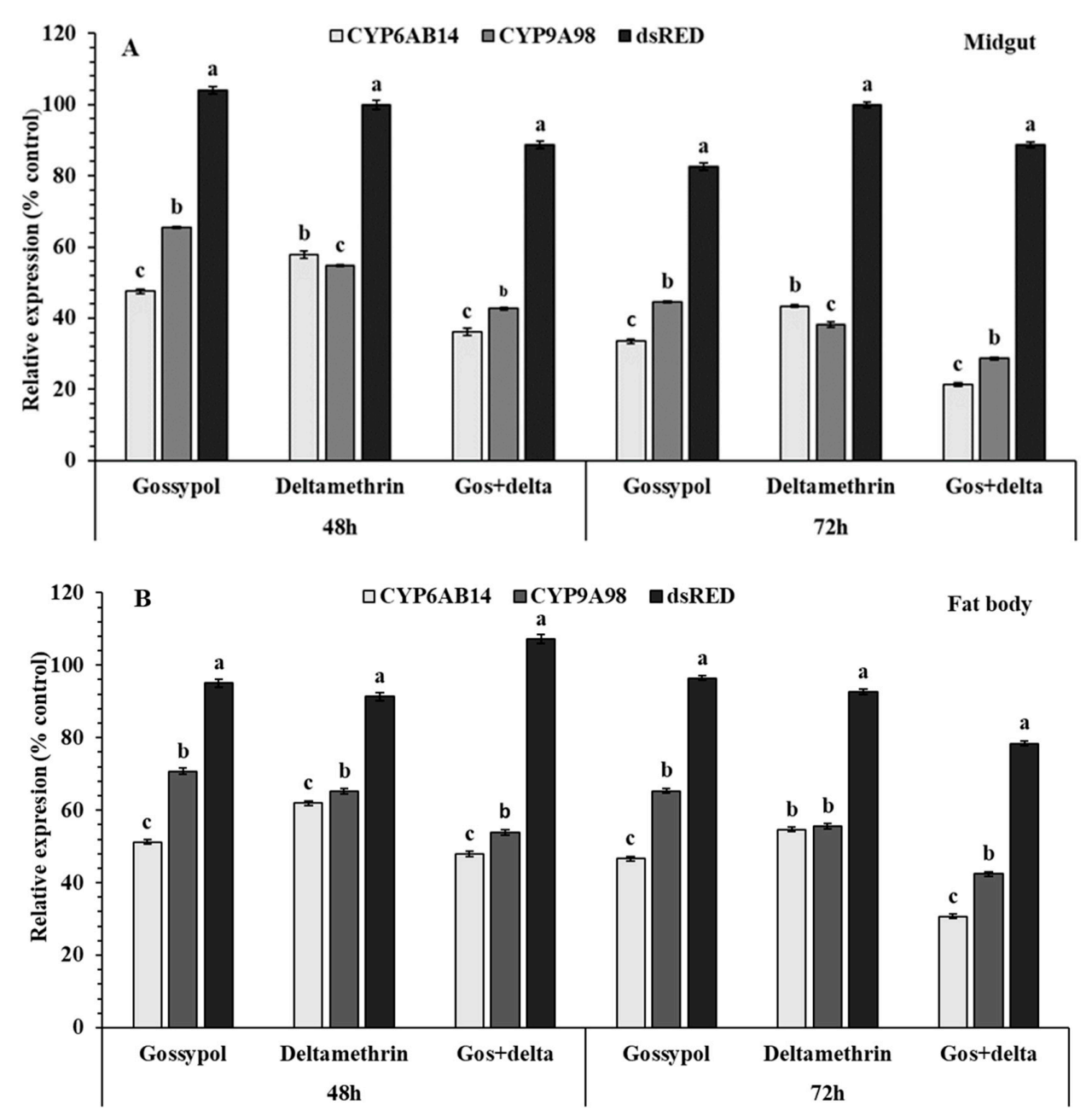

Figure 6. Effect of $d_{S C} C P A B 14$ and $d s C Y P A 98$ by droplet feeding on relative transcript levels in midguts (A) and fat bodies (B) after 48 and $72 \mathrm{~h}$ (A) on the fourth instar S. exigua larvae. Following the droplet-feeding with $d_{s C Y P A B 14}$ and $d s C Y P A 98$ or $d s R E D$ served as a control for $24 \mathrm{~h}$ then the exposed larvae were transferred individually into 12-oriface tissue culture plate containing artificial diets supplemented with $0.1 \%$ gossypol, LC $_{50}$ concentration of deltamethrin $0.887 \mathrm{mg} / \mathrm{L}$ for 48 and $72 \mathrm{~h}$ or $0.1 \%$ gossypol for $24 \mathrm{~h}$ followed by deltamethrin for 48 and $72 \mathrm{~h}$. Data shown are means $\pm \mathrm{SE}$ derived from three biological replicates. Different letters above bars indicate significant differences $(p<0.05)$ according to the Tukey HSD test. 


\section{Discussion}

The plant biochemical pathway leads to the production of a range of toxic compounds in response to the attack from pathogens or phytophagous insects [30,31]. Variation in defensive constituents of plant response to insect attack presents a variable challenge for insect herbivores, which in turn, affects their fitness and behavior [32,33]. Phytophagous insects protect themselves against these phytotoxic compounds by inducing detoxification genes in response to host plant secondary metabolites for their optimal growth and survival [14]. Usually, a P450 group may metabolize a single substrate in an alternate position or occasionally multiple substrates may be metabolized by a single P450 [14,34].

By ingesting one or more toxic compounds from host plants, phytophagous insects gain an enhanced tolerance to other toxic plant secondary metabolites and chemicals with directly pesticidal properties. The ability to gain tolerance based on post-exposure allows the insects to be highly adaptable to changes in their environment to acquire food from potentially harmful sources. Here we examined the effect of diet incorporation of plant allelochemicals on tolerance of S. exigua larvae to frequently used insecticides, deltamethrin in the field. In the present study, larvae of S. exigua that ingested gossypol, significantly enhanced tolerance to deltamethrin insecticide (Table 1). Present results support previous studies regarding gossypol pretreatment enhancing deltamethrin tolerance in lepidopteran, Helicoverpa armigera [16]. H. armigera has also been shown to display increased tolerance to lambda-cyhalothrin following exposure to quercetin in the larval diet [11]. In a similar approach with Helicoverpa Zea using a xanthotoxin pretreatment, it was shown that larvae demonstrated greater tolerance to alpha-cypermethrin [35] and four plant allelochemicals flavone, coumarin, DIMBOA (2,4-Dihydroxy-7-methoxy-1,4-benzoxazine-3-one), and visnagin significantly reduced larval sensitivity to methomyl in the larvae of Helicoverpa armigera [36]. In addition to Lepidoptera species, a similar phenomenon has also been observed in bee species (Hymenoptera: Apidae) using quercetin pretreatment to decrease sensitivity to tau-fluvalinate [37]. This is conceivable because of in response to selective agrochemicals; some detoxification enzymes, particularly P450s, have evolved the capability to metabolize synthetic insecticide in addition to their specific activity towards plant secondary metabolites.

It has been demonstrated that enhanced activity of detoxification P450 enzymes represents an important biochemical mechanism which metabolizes a wide array of toxic compounds including plant secondary metabolites and pesticides in phytophagous insects [14]. For example, numerous studies have revealed that the midguts and fat bodies of insect larvae play a dominant role in xenobiotic metabolism, and, therefore, detoxification activities of P450 enzymes may be highly expressed in these organs $[14,38]$. In this study, our results indicated that higher activity of the P450 detoxification enzyme was found in S. exigua larvae exposed to gossypol+deltamethrin after 48 and $72 \mathrm{~h}$ (Table 2). The results of the current study support previous work on various phytophagous insects, e.g., Spodoptera liture [16], H. armigera [11], who found that the acquired resistance of the plant defense chemicals is positively correlated with the resistance to some insecticides. In addition, exposure to $\mathrm{PBO}$, an important P450 synergist can inhibit the activity of P450 enzymes in phytophagous insects [39-41]. In this investigation, $\mathrm{PBO}$ showed synergetic effects on the toxicity of deltamethrin to the gossypol-fed larvae of S. exigua, thus, the results of the P450 synergist suggested that resistance to gossypol and deltamethrin is P450-mediated. Building on this evidence, these data suggest that the increased tolerance in S. exigua may result from the ability of these plant allelochemicals to induce detoxification enzymes, mainly P450s, which may contribute to the adaptation of polyphagous herbivores to the diverse allelochemicals encountered from their broad range of host plants.

Building on this evidence, these data support the case that the two gossypol-induced P450 genes are demonstrations of the evolutionary relationship between plants allelochemicals and pesticide detoxification. 
Table 2. Primers used in this study.

\begin{tabular}{|c|c|c|}
\hline Function & Primer Name & Primer Sequence $\left(5^{\prime}-3^{\prime}\right)$ \\
\hline \multicolumn{3}{|r|}{ Real-Time PCR } \\
\hline \multirow{2}{*}{ CYP6AB14 } & CYP6AB14-F & TCTTGATGCTGACTCGCTCA \\
\hline & CYP6AB14-R & TACAGGCTTCCGGGAACATT \\
\hline \multirow{2}{*}{ СУР9A98 } & CYP9A98-F & CTACCAGCATCTGCGTCAC \\
\hline & CYP9A98-R & TTAGCCTACACCTTAACCAAT \\
\hline \multirow{2}{*}{$\beta$-actin } & $\beta$-actin-F & ATCCTCCGTCTGGACTTGG \\
\hline & $\beta$-actin-R & GCACGATTTCCСТCTCA \\
\hline \multicolumn{3}{|r|}{ dsRNA synthesis } \\
\hline \multirow{5}{*}{ CYP6AB14 } & T7CYP6AB14-F1 & ggatcctaatacgactcactataggATGGGCTTTTCCAATCTTTC \\
\hline & CYP6AB14-R1 & GCTTAAACGTGCACAAGACAG \\
\hline & CYP6AB14-F2 & ATGGGCTTTTCCAATCTTTC \\
\hline & T7CYP6AB14-R2 & GCTTAAACGTGCACAAGACAGggatcctaatacgactcactatagg \\
\hline & T7CYP9A98-F1 & ggatcctaatacgactcactataggGAGAACTTCCTCAACCATCCTAA \\
\hline \multirow{3}{*}{ CYP9A98 } & CYP9A98-R1 & TGATTCCGCTAAGTATCTTTCCC \\
\hline & CYP9A98-F2 & GAGAACTTCСТСААССАТССТАA \\
\hline & T7CYP9A98-R2 & TGATTCCGCTAAGTATCTTTCCCggatcctaatacgactcactatagg \\
\hline \multirow{4}{*}{$d s R E D$} & T7dsRED-F1 & ggatcctaatacgactcactataggGCAAGCTATGCATCCAACGCGTTGGG \\
\hline & dsRED-R1 & CAAGCTATGCATCCAACGCGTTGGGAG \\
\hline & dsRED-F2 & GCAAGCTATGCATCCAACGCGTTGGG \\
\hline & T7dsRED-R2 & CAAGCTATGCATCCAACGCGTTGGGAGggatcctaatacgactcactatagg \\
\hline
\end{tabular}

In the present study, two cytochrome P450 genes induced in S. exigua larvae fed on gossypol-supplemented diet were shown to help metabolize phytotoxins and increase resistance to insecticides. Of specific importance, QRT-PCR results demonstrated that these two of gossypol-induced P450 genes (CYPAB14 and CYP9A98) were related to deltamethrin resistance (Figure 1). This builds on and takes forward those findings by demonstrating the effect of host plant secondary metabolites to induce detoxification enzymes that lead to enhanced insecticide tolerance in S. exigua. Detail of similar findings has been documented in previous studies. Gossypol-induced P450 genes (CYP6AE11, CYP321A1, CYP9A12, CYP9A14, and CYP6B7) have been documented by previous studies for cotton bollworm increased tolerance to deltamethrin [16]. Cytochrome P450 gene (CYP6AE14) was highly expressed in the midgut of cotton bollworm larvae exposed to a gossypol-supplemented diet [42]. Three P450 genes (CYP6B6, CYP6B8, and CYP321A1) have also shown up-regulation in quercetin-fed larvae of $H$. armigera which reduced the sensitivity to lambda-cyhalothrin [11]. Previous studies established that CYP9A105, CYP9A40, and CYP6AB14 are induced by deltamethrin, methoxyfenozide, and plant allelochemicals in S. litura and S. exigua $[41,43,44]$. Thus, the presence of highly active defensive compounds in host plant provides a selective pressure for the herbivorous insects to develop a rich pool of defense genes, which is at least one of the reasons why the larvae of beet armyworm have quickly acquired pyrethroid resistance.

RNA interference is a gene-blocking technique which has become well established in the past two decades and has been successfully used in the study of resistance mechanism and P450s function in many insect pests for resistance management [16,24,45-47]. RNAi-mediated silencing of insect target genes can be accomplished by introducing dsRNA molecules into the insect to reduce the expression of target genes at a transcriptional level. RNA-mediated interference has widely been used in insects can be achieved through the injection, oral ingestion, or droplet-feeding of dsRNA [16,24,41,48]. In present results, the transcript levels of target genes were significantly decreased when larvae were fed on dsRNA following the exposure to gossypol, deltamethrin, or gossypol+deltamethrin after 48 and $72 \mathrm{~h}$. Our present speculation is consistent with previous works [16,24,41]. Our results showed that RNAi-mediated silencing of CYP6AB14 and CYP9A98 significantly increased the mortality of S. exigua exposed to gossypol and deltamethrin-supplemented diet individually and gossypol+deltamethrin containing diet as compared with control treatment after 48 and $72 \mathrm{~h}$ (Figures 4 and 5). These findings 
of increased mortality are consistent with previous studies on cytochrome genes silencing [24,41,42,49]. Through dsRNA droplet feeding, we were able to lower expression levels of the target genes, which in turn reduced the gossypol-induced resistance to deltamethrin in the population of $S$. exigua.

In conclusion, at present, the rapid development of insecticide resistance of many insects and mites poses a major threat to agriculture all over the world. Based on the results in this study, the exposure of S. exigua larvae to gossypol reduces the sensitivity of the pest to a pyrethroid insecticide. We conclude from this that levels of cytochrome P450 detoxification enzymes play a crucial role in S. exigua larvae for the adaptation to plant secondary metabolites and synthetic insecticides. Feeding of $d s C Y P 6 A B 14$ and dsCYP9A98 increased the larval mortality of S. exigua when exposed to a diet containing gossypol and deltamethrin, which indicates that the genes involved in the detoxification of plant secondary metabolites and insecticides can serve as targets for insect pest control. Thus, besides directly impairing the insect growth and development, RNAi technology holds promise for overcoming insecticide resistance in pest populations and reducing the dosage of pesticides needed for effective pest control in the field.

\section{Materials and Methods}

\subsection{Insect Culture}

Beet armyworm (Spodoptera exigua) were collected from Jingzhou, Hubei, China in 2003. A colony was established in the laboratory and maintained at $25^{\circ} \mathrm{C}$ with $70 \%$ relative humidity under a $16 \mathrm{~h}$ light: $8 \mathrm{~h}$ dark photoperiod. Larvae were fed on artificial diet, as previously described by Mao et al. (2007) [42]. The insects were never exposed to any insecticides during the rearing.

\subsection{Chemicals}

Gossypol, 7.ethoxycoumarin, nicotinamide adenine dinucleotide phosphate (NADPH), piperonyl butoxide (PBO), 7-ethoxycoumarin, 7-hydroxycoumarin, Ethylenediaminetetraacetic acid (EDTA) and phenylmethylsulfonyl fluoride (PMSF) were bought from Sigma-Aldrich (St. Louis, MO, USA). Deltamethrin 25\% EC (Chimerical formulation) was obtained from Bayer crop science (Hang Zhou, China). Triton X-100 was from Amresco. Dithiothreitol (DTT), glycerol, and Tris were bought from Beijing Solarbio Scientific and Technology Company Beijing, China. Bovine serum albumin was purchased from Beyotime Biotechnology, Jiangsu, China. All chemicals and solvents used were reagent grade.

\subsection{Preparation of Treatment Diets}

The treatment diet was prepared according to the method described by [16] with slight modification; the $0.1 \%$ gossypol and $0.1 \%$ flavone to be tested were first dissolved in $1 \%$ dimethyl sulfoxide (DMSO). The control diet was prepared by adding the same volume of DMSO to the standard artificial diet. To achieve the desired concentration, serial dilutions were prepared from the stock solution of deltamethrin into distilled water. Five serial dilutions for treatment and control groups separately were prepared from the stock solution mixed in distilled water containing $0.1 \%$ Triton X-100 and added into the artificial diet before solidification of agar $\left(40-45^{\circ} \mathrm{C}\right)$, mixed gently and poured into new plastic cups ( $3 \mathrm{~cm}$ diameter, $3.5 \mathrm{~cm}$ height). The control diet was prepared by adding the same volume of DMSO to artificial diet but without gossypol, flavone or deltamethrin.

\subsection{Toxicological Analysis of Deltamethrin Tolerance in Larvae}

Effects of gossypol uptake on S. exigua larvae tolerance to deltamethrin were tested by feeding early third instar larvae on artificial diet containing $0.1 \%$ gossypol for 24 before the bioassay. For the control group, the artificial diet was prepared with the same method but without gossypol and flavone. A diet incorporation bioassay was used to determine the toxicity of deltamethrin to third instar larva of S. exigua following an established methodology [16]. A stock solution of deltamethrin 25 EC insecticide was prepared in distilled water containing $0.1 \%$ Triton X-100 and kept in contact with artificial food. 
Five serial dilutions $(10,5,2.5,1.25,0.625$, and $0.313 \mathrm{mg}$ of deltamethrin/L) for the treatment group and $(6,3,1.5,0.75,0.375$, and $0.1875 \mathrm{mg}$ of deltamethrin/L) for control group were then prepared from the stock solution and added into the artificial diet before solidification of agar $\left(40-45^{\circ} \mathrm{C}\right)$. Each was mixed gently and poured into a small, sterilized transparent plastic cup $(3 \mathrm{~cm}$ diameter, $3.5 \mathrm{~cm}$ height). The gossypol-pretreated third-stage larvae and those without pretreatment were transferred onto their diet medium. Each concentration was tested against 60 larvae (three groups of 20 larvae). Mortality was assayed after $24 \mathrm{~h}$ of deltamethrin application. The dead larvae were judged using a camel hairbrush, the Larvae were considered dead if they did not respond to the touch of a camel hair brush. The mortality rate is noted as the percentage found dead in each group.

\subsection{Effect of $P B O$ on the Toxicity of Insecticides}

To evaluate if the biochemical basis for tolerance involved P450s, the larvae exposed to the test chemicals were subjected to studies with known pesticide synergist, piperonyl butoxide (PBO). Potential synergy associated with $\mathrm{PBO}$ was determined using the bioassay methodology used for deltamethrin toxicity tests with the addition of $\mathrm{PBO}$ directly onto the larvae. A solution of PBO was prepared in $1 \%(v / v)$ acetone to the concentration of $25 \mathrm{mg} / \mathrm{mL}$. After S. exigua larvae fed on the gossypol-supplemented diet for $24 \mathrm{~h}, 10 \mu \mathrm{g}$ of $\mathrm{PBO}$ solution was topically delivered onto the dorsal prothorax of each individual larvae using Micro4 ${ }^{\mathrm{TM}}$ MicroSyringe Pump Controller (USA). After $2 \mathrm{~h}$, the PBO-treated larvae were transferred into new cups containing the artificial diet supplemented with different concentration of deltamethrin $(6,3,1.5,0.75,0.375$, and $0.1875 \mathrm{mg}$ of deltamethrin/L). The control group larvae were prepared using the same methodology (including gossypol pretreatment) but without exposure to PBO. Each concentration contained 60 larvae (20 larvae were tested in each of three replicates). Mortality was recorded after $24 \mathrm{~h}$, and the $\mathrm{LC}_{50}$ values were calculated [11]. The synergism ratio (SR) was calculated by dividing the $\mathrm{LC}_{50}$ of insecticide alone by $\mathrm{LC}_{50}$ of insecticide plus synergist [50].

\subsection{The Effect of $0.1 \%$ Gossypol Diet on Bodyweight}

To evaluate the effect of gossypol on the growth of S. exigua, 120 third instar larvae with uniform size were starved for $2 \mathrm{~h}$ and transferred to the sterilized transparent plastic cup $(3 \mathrm{~cm}$ diameter, $3.5 \mathrm{~cm}$ height) containing the artificial diet supplemented with $0.1 \%$ gossypol and control (CK) diet without gossypol for 1 day. After $24 \mathrm{~h}$, they were weighed and transferred to a diet containing $0.887 \mathrm{mg} / \mathrm{L}$ deltamethrin (a sublethal concentration) for another $24 \mathrm{~h}$. After 2 days of exposure, the net weight increase was recorded.

\subsection{Samples Preparation for P450 Enzyme Activity}

The detoxification enzyme P450 activity in the early fourth instar of S. exigua larvae midgut homogenates was assayed. Measurements were taken after they were reared on a diet containing $1.0 \mathrm{mg} / \mathrm{g}$ gossypol or no gossypol (control) for one day. After $24 \mathrm{~h}$ the exposed larvae were placed into new sterilized plastic cups containing artificial diets supplemented with $0.1 \%$ gossypol, $\mathrm{LC}_{50}$ concentration of deltamethrin $0.887 \mathrm{mg} / \mathrm{L}$ for 48 and $72 \mathrm{~h}$, or $0.1 \%$ gossypol for $24 \mathrm{~h}$ followed by deltamethrin for 48 and $72 \mathrm{~h}$. The midgut was removed after 48 or $72 \mathrm{~h}$ for further analysis. The midguts from all treatments were extracted by dissection on ice. The dissected midguts were gently shaken to free its contents and washed in a cold aqueous solution containing $1.15 \%(w / v)$ potassium chloride. The crude homogenates of treated and control S. exigua midguts were prepared as previously described by Liu et al. [51] with some modification for enzymes activity assay. All experiments were performed in triplicate.

\subsection{Measurement of P450 Enzyme Activity}

The 7-ethoxycoumarin-O-deethylase (ECOD) activity of cytochrome P450 enzyme in the midguts of S. exigua larvae using 7-ethoxycoumarin (7-EC) was measured as the substrate according to the method described by (Chen et al. 2017) [11]. Approximately, fifteen midguts third-instar larvae of $S$. 
exigua were homogenized on ice with $2 \mathrm{~mL}$ of homogenization buffer $0.1 \mathrm{M}$ PBS at $\mathrm{pH} 7.5$ containing 1.0 mM EDTA, 1.0 mM phenylmethylsulfonyl fluoride (PMSF), $1.0 \mathrm{mM} \mathrm{PTU,} 0.1 \mathrm{mM}$ DTT, and 15\% glycerol, followed by the centrifugation at $12,000 \mathrm{~g}$ for $12 \mathrm{~min}$ at $4{ }^{\circ} \mathrm{C}$. The supernatant from centrifuged 2 -mL tubes was collected and further used for P450s activity assay. The reaction solutions containing a total of $20 \mu \mathrm{L}$ of NADPH (10 mM stock solution) and $25 \mu \mathrm{L}$ of 7-EC (10 mM stock solution) in $685 \mu \mathrm{L}$ solution of $0.1 \mathrm{M}$ Tris-HCl buffer ( $\mathrm{pH} 7.8$ ) and $250 \mu \mathrm{L}$ of the enzyme homogenate was added to start the enzyme reaction. The incubation was conducted on a shaker for $15 \mathrm{~min}$ at $30^{\circ} \mathrm{C}$, and a $300-\mu \mathrm{L}$ solution of $15 \%(\mathrm{w} / \mathrm{v})$ trichloroacetic acid (TCA) was added to terminate the reactions. The mixture in 2-mL tubes was centrifuged at $10,800 \mathrm{~g}$ at $4{ }^{\circ} \mathrm{C}$ for $2 \mathrm{~min}$, with around $800 \mu \mathrm{L}$ of supernatant from tubes being transferred to new 2-mL tubes, and a $450-\mu \mathrm{L}$ solution containing $1.6 \mathrm{M}$ Gly-NaOH buffer ( $\mathrm{pH}$ 10.5) was added to adjust the $\mathrm{pH} 10$ of resulting extract. The content of 7-hydroxycoumarin in the reaction mixture was measured immediately by using a SPECTRA max GEMINI XS spectrofluorometer (Molecular Devices, USA) with adjusting $356 \mathrm{~nm}$ excitation and $465 \mathrm{~nm}$ emission filters. A series of different concentrations of 7-hydroxycoumarin were prepared, and standard substance fluorescence values were measured to draw the standard curves. All biochemical assays were conducted at least three replicates with different preparations of enzymes. Each of three replicate consisted of five midguts. Protein concentration was determined using the method described by Bradford [52] but with bovine serum albumin as the standard protein.

\subsection{Sample Preparation}

To determine tissue-specific expression patterns for the target genes, the third instar larvae were transferred into new sterilized plastic cups containing artificial diets supplemented with $0.1 \%$ gossypol, $\mathrm{LC}_{50}$ concentration of deltamethrin $0.887 \mathrm{mg} / \mathrm{L}$ for $72 \mathrm{~h}$ or $0.1 \%$ gossypol for $24 \mathrm{~h}$ followed by deltamethrin for $72 \mathrm{~h}$ and $1.0 \mathrm{mg} / \mathrm{g}$ DMSO for the control group. After $72 \mathrm{~h}$ of chemical induction, the midguts and fat bodies tissues were taken from all treatments including control and stored at $-80{ }^{\circ} \mathrm{C}$ for RNA extraction. Each treatment had three biological replicates.

\subsection{RNA Extraction and cDNA Synthesis}

The fourth instar larvae of $S$. exigua were dissected to harvest midguts, fat bodies, and cuticle. Total RNA was prepared using the Trizol reagent according to the manufacturer's protocol (Takara, Japan), and treated with DNase I (Qiagen, Valencia, CA, USA). The concentration and purity of total RNA were determined by a NanoDrop ${ }^{\circledR}$ spectrophotometer (Thermo Fisher, MA, USA) and RNA integrity was examined by agarose gel electrophoresis. First-strand complementary DNA (cDNA) was synthesized by using TransScript ${ }^{\circledR}$ One-Step gDNA Removal and cDNA Synthesis SuperMix in $20 \mu \mathrm{L}$ reactions containing $1 \mu \mathrm{g}$ of total RNA (500 ng), $1 \mu \mathrm{L}$ Anchord Oligo(dT) ${ }_{18}$ Prime $(0.5 \mu \mathrm{g} / \mu \mathrm{L}), 10 \mu \mathrm{L} 2 \times \mathrm{TS}$ Reaction mixture, TransScript ${ }^{\circledR}$ RT/RI Enzyme Mix and gDNA Remover at $42{ }^{\circ} \mathrm{C}$ for $30 \mathrm{~min}$. Three independent RNA preparations representing three biological replicates were used for cDNA synthesis.

\subsection{Quantitative Real-Time PCR}

The expression levels of cytochrome P450 genes were quantified by quantitative real-time PCR (qRT-PCR) using an MYiQ' RT-PCR system Bio-Rad, California, USA) and Real Master Mix 2xSYBR Green qPCR mix (Aidlab Biotechnologies Co., Ltd., China). QRT-PCR of each cDNA sample and template-free was performed in triplicate. Specific primers of CYP6AB14 and CYP9A98 were designed for qPCR (Table 2). Reaction volume of $20 \mu \mathrm{l}$ was used $(0.5 \mu \mathrm{L}$ of each primer $10 \mu \mathrm{M}, 1 \mu \mathrm{L}$ cDNA, $8 \mathrm{ul}$ $\mathrm{ddH} 20$ and $10 \mu \mathrm{L} 2 \mathrm{x}$ cyber master mix for quantification using the following cycling parameters: $94{ }^{\circ} \mathrm{C}$ for $3 \mathrm{~min}$, followed by $40 \mathrm{cycles}$ of $94{ }^{\circ} \mathrm{C}$ for $15 \mathrm{sec}, 57-60^{\circ} \mathrm{C}$ for $30 \mathrm{~s}$ and $70{ }^{\circ} \mathrm{C}$ for $30 \mathrm{~s}$. For each gene, a serial dilution from 10- to 1000-fold of each cDNA template was performed to assess the efficiency of PCR. The relative expression values were calculated using the $2^{-\Delta \Delta C T}$ methods as previously described by Livak and Schmittgen (2001). Results were expressed as the mean expression ratio $( \pm$ S.E.) and each sample, including control, was run in three replicates. One-way analysis of variance (ANOVA) and 
the Tukey HSD test for the significant difference was performed to determine the statistical difference between means (SPSS, version 19).

\subsection{Preparation of $d s R N A$}

For dsRNA synthesis, a 405 bp fragment of CYP6AB14 (GenBank accession KX443423) and a 358 bp fragment of CYP9A98 (GenBank accession KX443440) were amplified by PCR. The primers used for the CYP6AB14, CYP9A98, and dsRED amplifications were designed to add the T7 polymerase promoter sequence to the $5^{\prime}$ end of each strand (Table 2). Similarly, the $d s R E D$ as a control was prepared using the same method by designing the two pairs of primer (T7RED-F and RED-R, RED-F and T7RED-R) (Table 2). The $d s R E D$ reference template was provided by the Dr. Xianchun Li laboratory (University of Arizona). The $d_{s C Y}$ P6AB14, $d_{s C Y P 9 A 98}$, and $d s R E D$ were prepared from the purified PCR-generated templates according to the instructions and method provided with the T7 RiboMax Express RNAi System kit (Promega, Madison, WI, USA). The dsRNA was then purified by using MEGA clear ${ }^{\mathrm{TM}}$ Kit (Ambion). The resulting dsRNAs from all genes including control gene were quantified by a NanoDrop ${ }^{\circledR}$ spectrophotometer (Thermo Fisher, MA, USA) and integrity was analyzed by agarose gel electrophoresis, and then stored at $-80^{\circ} \mathrm{C}$ prior to use.

\subsection{Administration of dsRNA by Droplet-Feeding}

To prevent the damage to $S$. exigua larvae, we used a droplet-feeding method for RNAi interference [24,53,54]. For RNAi bioassays, double-stranded RNAs (dsRNA) dissolved in diethylpyrocarbonate (DEPC)-treated water. The fourth instar larvae were placed individually in 12-orifice tissue culture plates and starved for $6 \mathrm{~h}$. The dsRNA solution $(500 \mu \mathrm{g} / \mu \mathrm{l})$ was configured by dissolving in DEPC treated water. The starved larvae were placed individually in 12-orifice tissue culture plate containing the artificial diet and one drop $0.5 \mu \mathrm{l}(500 \mu \mathrm{g} / \mu \mathrm{l})$ of dsRNA solution was placed near each larval mouth using a Microliter Syringe Beijing Karaltay Scientific Instruments Co., Ltd. Twenty-four hours after feeding on dsRNA larvae were subjected to toxicity analysis.

For toxicity analysis, after $24 \mathrm{~h}$ of dsRNA post-feeding, $60 \mathrm{~S}$. exigua larvae for each independent treatment (Each of three replicate consisted of 20 larvae) were transferred individually into 12-orifice tissue culture plate containing artificial diets supplemented with $0.1 \%$ gossypol, $\mathrm{LC}_{50}$ concentration of deltamethrin $0.887 \mathrm{mg} / \mathrm{L}$ for $72 \mathrm{~h}$, and $0.1 \%$ gossypol for $24 \mathrm{~h}$ followed by deltamethrin for $72 \mathrm{~h}$ and standard diet. A non-supplemented diet was used as a control group. The mortality data were recorded at 48 and $72 \mathrm{~h}$ after feeding of dsRNA on different treatments including control. All experiments were performed in triplicate.

\subsection{Combined Effects of dsRNA on Mortality}

Similarly, the combined effect of two target genes (CYP6AB14 and CYP9A98) was analyzed by mixing an equal volume of each dsRNA to obtain a $1.0 \mu \mathrm{L}(1000 \mu \mathrm{g} / \mu \mathrm{L})$ concentration. The feeding assay was performed for all treatments by a droplet-feeding method as described above.

For toxicity analysis, after $24 \mathrm{~h}$ of dsRNA feeding, $60 \mathrm{~S}$. exigua larvae for each independent treatment (Each of three replicate consisted of 20 larvae) were transferred individually into 12-orifice tissue culture plate containing artificial diets supplemented with $0.1 \%$ gossypol, $\mathrm{LC}_{50}$ concentration of deltamethrin $0.887 \mathrm{mg} / \mathrm{L}$ for $72 \mathrm{~h}$, and $0.1 \%$ gossypol for $24 \mathrm{~h}$ followed by deltamethrin for $72 \mathrm{~h}$ and standard diet. A non-supplemented diet was used as a control group. The mortality data were recorded at 48 and $72 \mathrm{~h}$ after feeding of dsRNA on different treatments including control. All experiments were performed in triplicate.

\subsection{Analysis of the Silencing Effect}

To assess the expression level associated with each treatment by using qRT-PCR, approximately fifteen midguts and fat bodies (for each of three replicate) from surviving larvae were collected for total RNA extraction at two times (48 and $72 \mathrm{~h}$ ). Quantitative RT-PCR was performed as described earlier. 


\subsection{Statistical Analysis}

All data were analyzed using the SPSS 20.0 Software Package (SPSS Inc., Chicago, IL, USA). One-way ANOVA followed by the Tukey HSD test was employed to analyze differences between tissues and developmental stages. A Student's t-test was used to analyze data from the RNAi and feeding experiments with chemicals.

Supplementary Materials: Supplementary materials can be found at http://www.mdpi.com/1422-0067/20/9/2248/s1.

Author Contributions: Conceived of and designed the experiments: M.H., M.W., and S.L.; Performed the experiments: M.H., S.L. and L.S.; Analysis of the data: M.H., S.L., S.J. and B.A.; drafted and revised manuscript: M.H., S.L., S.J., G.M.F.-G., A.G. and M.R. All authors approved the final version of the article, including the authorship list.

Funding: This work was supported by the National Natural Science Foundation of China (Grant 31171874) [M.W]), Grant 31701791 (S.L.), Hubei Provincial Natural Science Foundation of China (Grant 2017CFB233 [S.L.]), Fundamental Research Funds for the Central Universities (Grant 52902-0900202797 [S.L.]), and the China Scholarship Council (CSC) to Muhammad Hafeez.

Conflicts of Interest: The authors declare no conflict of interest.

\section{References}

1. Taggar, G.K.; Gill, R.S. Host plant resistance in Vigna sp. towards whitefly, Bemisia tabaci (Gennadius): A review. Entomol. Gen. 2016, 36, 1-24. [CrossRef]

2. Fürstenberg-Hägg, J.; Zagrobelny, M.; Bak, S. Plant Defense against Insect Herbivores. Int. J. Mol. Sci. 2013, 14, 10242-10297. [CrossRef]

3. War, A.R.; Paulraj, M.G.; War, M.Y.; Ignacimuthu, S. Herbivore- and elicitor-induced resistance in groundnut to Asian armyworm, Spodoptera litura (Fab.) (lepidoptera: Noctuidae). Plant Signal. Behav. 2011, 6, 1769-1777. [CrossRef]

4. Lattanzio, V.; Arpaia, S.; Cardinali, A.; Di Venere, D.; Linsalata, V. Endogenous flavonoids in resistance mechanism of Vigna role of to aphids. J. Agric. Food Chem. 2000, 48, 5316-5320. [CrossRef]

5. Salunke, B.K.; Kotkar, H.M.; Mendki, P.S.; Upasani, S.M.; Maheshwari, V.L. Efficacy of flavonoids in controlling Callosobruchus chinensis (L.) (Coleoptera: Bruchidae), a post-harvest pest of grain legumes. Crop Prot. 2005, 24, 888-893. [CrossRef]

6. Duisembecova, B.A.; Dubovskiyb, I.M.; Glupov, V.V. Effect of plant secondary metabolites on susceptibility of insects to entomopathogenic microorganisms. Contemp. Probl. Ecol. 2017, 10, 286-292. [CrossRef]

7. Wang, X.; Howell, C.P.; Chen, F.; Yin, J.; Jiang, Y. Gossypol-A polyphenolic compound from cotton plant. Adv. Food Nutr. Res. 2009, 58, 215-263.

8. Krempl, C.; Heidel-Fischer, H.M.; Jiménez-Alemán, G.H.; Reichelt, M.; Menezes, R.C.; Boland, W.; Vogel, H.; Heckel, D.G.; Joußen, N. Gossypol toxicity and detoxification in Helicoverpa armigera and Heliothis virescens. Insect Biochem. Mol. Biol. 2016, 78, 69-77. [CrossRef]

9. Vontas, J.G.; Small, G.J.; Hemingway, J. Glutathione S-transferases as antioxidant defence agents confer pyrethroid resistance in Nilaparvata lugens. Biochem. J. 2001, 357, 65-72. [CrossRef]

10. Feyereisen, R. Insect Cytochrome P450. In Comprehensive Molecular Insect Science; Elsevier: Amsterdam, The Netherlands, 2005; pp. 1-77. ISBN 0-44-451524-0.

11. Chen, C.; Liu, Y.; Shi, X.; Desneux, N.; Han, P.; Gao, X. Elevated carboxylesterase activity contributes to the lambda-cyhalothrin insensitivity in quercetin fed Helicoverpa armigera (Hübner). PLoS ONE 2017, e0183111. [CrossRef]

12. Mao, Y.B.; Tao, X.Y.; Xue, X.Y.; Wang, L.J.; Chen, X.Y. Cotton plants expressing CYP6AE14 double-stranded RNA show enhanced resistance to bollworms. Transgenic Res. 2011, 20, 665-673. [CrossRef]

13. Li, X.; Schuler, M.A.; Berenbaum, M.R. Molecular Mechanisms of Metabolic Resistance to Synthetic and Natural Xenobiotics. Annu. Rev. Entomol. 2007, 52, 231-253. [CrossRef]

14. Schuler, M.A. P450s in plant-insect interactions. Biochim. Biophys. Acta-Proteins Proteomics 2011, 1814, 36-45. [CrossRef]

15. Hu, B.; Zhang, S.H.; Ren, M.M.; Tian, X.R.; Wei, Q.; Mburu, D.K.; Su, J.Y. The expression of Spodoptera exigua P450 and UGT genes: Tissue specificity and response to insecticides. Insect Sci. 2017, 26, 199-216. [CrossRef] 
16. Tao, X.Y.; Xue, X.Y.; Huang, Y.P.; Chen, X.Y.; Mao, Y.B. Gossypol-enhanced P450 gene pool contributes to cotton bollworm tolerance to a pyrethroid insecticide. Mol. Ecol. 2012, 21, 4371-4385. [CrossRef]

17. Mao, W.; Rupasinghe, S.G.; Johnson, R.M.; Zangerl, A.R.; Schuler, M.A.; Berenbaum, M.R. Quercetin-metabolizing CYP6AS enzymes of the pollinator Apis mellifera (Hymenoptera: Apidae). Comp. Biochem. Physiol. - B Biochem. Mol. Biol. 2009, 154, 427-434. [CrossRef]

18. Wee, C.W.; Lee, S.F.; Robin, C.; Heckel, D.G. Identification of candidate genes for fenvalerate resistance in Helicoverpa armigera using cDNA-AFLP. Insect Mol. Biol. 2008, 17, 351-360. [CrossRef]

19. Zhao, C.; Tang, T.; Feng, X.; Qiu, L. Cloning and characterisation of NADPH-dependent cytochrome P450 reductase gene in the cotton bollworm, Helicoverpa armigera. Pest Manag. Sci. 2014, 555, 262-270. [CrossRef]

20. Li, X.; Berenbaum, M.R.; Schuler, M.A. Molecular cloning and expression of CYP6B8: A xanthotoxin-inducible cytochrome P450 cDNA from Helicoverpa zea. Insect Biochem. Mol. Biol. 2000, 30, 75-84. [CrossRef]

21. Xie, W.; Wang, S.; Wu, Q.; Feng, Y.; Pan, H.; Jiao, X.; Zhou, L.; Yang, X.; Fu, W.; Teng, H.; et al. Induction effects of host plants on insecticide susceptibility and detoxification enzymes of Bemisia tabaci (Hemiptera: Aleyrodidae). Pest Manag. Sci. 2011, 67, 87-93. [CrossRef]

22. Uğurlu Karaağaç, S.; Konuş, M.; Büyük, M. Determination of susceptibility levels of Helicoverpa armigera (Hübner) (Noctuidae: Lepidoptera) strains collected from different regions to some insecticides in Turkey. J. Entomol. Res. Soc. 2013, 15, 37-45.

23. Qiu, L.; Hou, L.; Zhang, B.; Liu, L.; Li, B.; Deng, P.; Ma, W.; Wang, X.; Fabrick, J.A.; Chen, L.; et al. Cadherin is involved in the action of Bacillus thuringiensis toxins Cry1Ac and Cry2Aa in the beet armyworm, Spodoptera exigua. J. Invertebr. Pathol. 2015, 127, 47-53. [CrossRef]

24. Wang, X.; Chen, Y.; Gong, C.; Yao, X.; Jiang, C.; Yang, Q. Molecular identification of four novel cytochrome P450 genes related to the development of resistance of Spodoptera exigua (Lepidoptera: Noctuidae) to chlorantraniliprole. Pest Manag. Sci. 2018. [CrossRef]

25. Lai, T.; Li, J.; Su, J. Monitoring of beet armyworm Spodoptera exigua (Lepidoptera: Noctuidae) resistance to chlorantraniliprole in China. Pestic. Biochem. Physiol. 2011, 101, 198-205. [CrossRef]

26. Tian, X.; Sun, X.; Su, J. Biochemical mechanisms for metaflumizone resistance in beet armyworm, Spodoptera exigua. Pestic. Biochem. Physiol. 2014, 113, 8-14. [CrossRef]

27. Wang, X.; Xiang, X.; Yu, H.; Liu, S.; Yin, Y.; Cui, P.; Wu, Y.; Yang, J.; Jiang, C.; Yang, Q. Monitoring and biochemical characterization of beta-cypermethrin resistance in Spodoptera exigua (Lepidoptera: Noctuidae) in Sichuan Province, China. Pestic. Biochem. Physiol. 2018, 146, 71-89. [CrossRef]

28. Ishtiaq, M.; Saleem, M.A.; Razaq, M. Monitoring of resistance in Spodoptera exigua (Lepidoptera: Noctuidae) from four districts of the Southern Punjab, Pakistan to four conventional and six new chemistry insecticides. Crop Prot. 2012, 33, 13-20. [CrossRef]

29. Tian, H.; Peng, H.; Yao, Q.; Chen, H.; Xie, Q.; Tang, B.; Zhang, W. Developmental control of a lepidopteran pest Spodoptera exigua by ingestion of bacteria expressing dsRNA of a non-midgut gene. PLoS ONE 2009, 4, e6225. [CrossRef]

30. Stam, J.M.; Kroes, A.; Li, Y.; Gols, R.; van Loon, J.J.A.; Poelman, E.H.; Dicke, M. Plant Interactions with Multiple Insect Herbivores: From Community to Genes. Annu. Rev. Plant Biol. 2014, 65, 689-713. [CrossRef]

31. Holm Freiesleben, S.; Jäger, A.K. Correlation between plant secondary metabolites and their antifungal mechanisms-A review. Med. Aromat. Plants 2014. [CrossRef]

32. Rani, P.U.; Jyothsna, Y. Biochemical and enzymatic changes in rice plants as a mechanism of defense. Acta Physiol. Plant. 2010, 32, 695-701. [CrossRef]

33. Bos, N.; Lefèvre, T.; Jensen, A.B.; d'Ettorre, P.; Schluns, H.; Crozier, R.H.; Moret, Y.; Schmid-Hempel, P.; Tsakas, S.M.V.J.; Zhang, J.; et al. Herbivores: Their Interactions with Secondary Plant Metabolites: The Chemical Participants. Evolution (N. Y). 2012, 7, 481.

34. Chen, C.; Han, P.; Yan, W.; Wang, S.; Shi, X.; Zhou, X.; Desneux, N.; Gao, X. Uptake of quercetin reduces larval sensitivity to lambda-cyhalothrin in Helicoverpa armigera. J. Pest Sci. 2018, 91, 919-926. [CrossRef]

35. Li, X.C.; Zangerl, A.R.; Schuler, M.A.; Berenbaum, B.M. Cross-resistance to $\alpha$-cypermethrin after xanthotoxin ingestion in Helicoverpa zea (Lepidoptera: Noctuidae). J. Econ. Entomol. 2000, 93, 18-25. [CrossRef]

36. Chen, S.; Elzaki, M.E.A.; Ding, C.; Li, Z.F.; Wang, J.; Zeng, R.S.; Song, Y.Y. Plant allelochemicals affect tolerance of polyphagous lepidopteran pest Helicoverpa armigera (Hübner) against insecticides. Pestic. Biochem. Physiol. 2019, 154, 32-38. [CrossRef] 
37. Johnson, R.M.; Mao, W.; Pollock, H.S.; Niu, G.; Schuler, M.A.; Berenbaum, M.R. Ecologically appropriate xenobiotics induce cytochrome P450s in Apis Mellifera. PLoS ONE 2012, 7, e31051. [CrossRef]

38. Scott, J.G. Cytochromes P450 and insecticide resistance. Insect Biochem. Mol. Biol. 1999, 29, 757-777. [CrossRef]

39. Hafeez, M.; Liu, S.; Jan, S.; Ali, B.; Shahid, M.; Fernández-Grandon, G.M.; Nawaz, M.; Ahmad, A.; Wang, M. Gossypol-induced fitness gain and increased resistance to deltamethrin in beet armyworm, Spodoptera exigua (Hübner). Pest Manag. Sci. 2018, 75, 683-693. [CrossRef]

40. Iwasa, T.; Motoyama, N.; Ambrose, J.T.; Roe, R.M. Mechanism for the differential toxicity of neonicotinoid insecticides in the honey bee, Apis mellifera. Crop Prot. 2004. [CrossRef]

41. Wang, R.L.; Liu, S.W.; Baerson, S.R.; Qin, Z.; Ma, Z.H.; Su, Y.J.; Zhang, J.E. Identification and functional analysis of a novel cytochrome P450 gene CYP9A105 associated with pyrethroid detoxification in Spodoptera exigua hübner. Int. J. Mol. Sci. 2018, 19, 737. [CrossRef]

42. Mao, Y.B.; Cai, W.J.; Wang, J.W.; Hong, G.J.; Tao, X.Y.; Wang, L.J.; Huang, Y.P.; Chen, X.Y. Silencing a cotton bollworm P450 monooxygenase gene by plant-mediated RNAi impairs larval tolerance of gossypol. Nat. Biotechnol. 2007, 25, 1307-1313. [CrossRef]

43. Wang, R.L.; Li, J.; Staehelin, C.; Xin, X.W.; Su, Y.J.; Zeng, R. Sen Expression Analysis of Two P450 Monooxygenase Genes of the Tobacco Cutworm Moth (Spodoptera litura) at Different Developmental Stages and in Response to Plant Allelochemicals. J. Chem. Ecol. 2014, 41, 111-119. [CrossRef]

44. Wang, R.L.; Xia, Q.Q.; Baerson, S.R.; Ren, Y.; Wang, J.; Su, Y.J.; Zheng, S.C.; Zeng, R. Sen A novel cytochrome P450 CYP6AB14 gene in Spodoptera litura (Lepidoptera: Noctuidae) and its potential role in plant allelochemical detoxification. J. Insect Physiol. 2015, 75, 54-62. [CrossRef]

45. Wang, R.-L.; Staehelin, C.; Xia, Q.-Q.; Su, Y.-J.; Zeng, R.-S. Identification and Characterization of CYP9A40 from the Tobacco Cutworm Moth (Spodoptera litura), a Cytochrome P450 Gene Induced by Plant Allelochemicals and Insecticides. Int. J. Mol. Sci. 2015, 16, 22606-22620. [CrossRef]

46. Wang, R.-L.; He, Y.-N.; Staehelin, C.; Liu, S.-W.; Su, Y.-J.; Zhang, J.-E. Identification of Two Cytochrome Monooxygenase P450 Genes, CYP321A7 and CYP321A9, from the Tobacco Cutworm Moth (Spodoptera Litura) and Their Expression in Response to Plant Allelochemicals. Int. J. Mol. Sci. 2017, 18, 2278. [CrossRef]

47. Shi, L.; Zhang, J.; Shen, G.; Xu, Z.; Xu, Q.; He, L. Collaborative contribution of six cytochrome P450 monooxygenase genes to fenpropathrin resistance in Tetranychus cinnabarinus (Boisduval). Insect Mol. Biol. 2016. [CrossRef]

48. Jan, S.; Liu, S.; Hafeez, M.; Zhang, X.; Dawar, F.U.; Guo, J.; Gao, C.; Wang, M. Isolation and functional identification of three cuticle protein genes during metamorphosis of the beet armyworm, Spodoptera exigua. Sci. Rep. 2017. [CrossRef]

49. Zhu, W.; Yu, R.; Wu, H.; Zhang, X.; Liu, Y.; Zhu, K.Y.; Zhang, J.; Ma, E. Identification and characterization of two CYP9A genes associated with pyrethroid detoxification in Locusta migratoria. Pestic. Biochem. Physiol. 2016, 132, 65-71. [CrossRef]

50. Wang, R.L.; Zhu-Salzman, K.; Baerson, S.R.; Xin, X.W.; Li, J.; Su, Y.J.; Zeng, R. Sen Identification of a novel cytochrome P450 CYP321B1 gene from tobacco cutworm (Spodoptera litura) and RNA interference to evaluate its role in commonly used insecticides. Insect Sci. 2017, 24, 235-247. [CrossRef]

51. Liu, X.; Liang, P.; Gao, X.; Shi, X. Induction of the cytochrome P450 activity by plant allelochemicals in the cotton bollworm, Helicoverpa armigera (Hübner). Pestic. Biochem. Physiol. 2006, 84, 127-134. [CrossRef]

52. Bradford, M.M. A rapid and sensitive method for the quantitation of microgram quantities of protein utilizing the principle of protein-dye binding. Anal. Biochem. 1976, 84, 127-134. [CrossRef]

53. Livak, K.J.; Schmittgen, T.D. Analysis of relative gene expression data using real-time quantitative PCR and the 2(-Delta Delta C(T)) Method. Methods 2001, 25, 402-408. [CrossRef]

54. Bautista, M.A.M.; Miyata, T.; Miura, K.; Tanaka, T. RNA interference-mediated knockdown of a cytochrome P450, CYP6BG1, from the diamondback moth, Plutella xylostella, reduces larval resistance to permethrin. Insect Biochem. Mol. Biol. 2009, 39, 38-46. [CrossRef]

(C) 2019 by the authors. Licensee MDPI, Basel, Switzerland. This article is an open access article distributed under the terms and conditions of the Creative Commons Attribution (CC BY) license (http://creativecommons.org/licenses/by/4.0/). 